\title{
Herdabilidade e correlação fenotípica de caracteres relacionados à produtividade de grãos e à morfologia da canola
}

\author{
Cleusa Adriane Menegassi Bianchi Krüger ${ }^{(1)}$, José Antonio Gonzalez da Silva(1), \\ Sandro Luis Petter Medeiros ${ }^{(2)}$, Genei Antonio Dalmago ${ }^{(3)}$ e Juliano Gaviraghi( ${ }^{(1)}$
}

(1)Universidade Regional do Noroeste do Estado do Rio Grande do Sul, Departamento de Estudos Agrários, Rua do Comércio,
oㅡ 3.000, CEP 98700-000 ljuí, RS. E-mail: cleusa_bianchi@yahoo.com.br, jagsfaem@yahoo.com.br, gaviraghi_juli@hotmail.com
(2)Universidade Federal de Santa Maria, Centro de Ciências Rurais, Departamento de Fitotecnia, CEP 97105-900 Santa Maria, RS.
E-mail: slpmedeiros@yahoo.com.br ${ }^{(3)}$ Embrapa Trigo, Caixa Postal 451, CEP 99001-970 Passo Fundo, RS. E-mail: dalmago@cnpt.embrapa.br

Resumo - O objetivo deste trabalho foi estimar a herdabilidade e avaliar a correlação fenotípica entre caracteres de canola (Brassica napus) relacionados à produtividade de grãos e à arquitetura de plantas. Foram realizados três experimentos, com espaçamento entre linhas de 0,20, 0,40 e 0,60 m. Durante dois anos de cultivo (2008 e 2009), os genótipos 'Hyola 432' e 'Hyola 61' foram avaliados em quatro densidades de plantio (20, 40, 60 e 80 plantas por metro quadrado), em cada experimento. Empregou-se o delineamento de blocos ao acaso, em arranjo fatorial 2x2x4 (anos x genótipos $\mathrm{x}$ densidades), com quatro repetições. Foram avaliados componentes ligados à produção (produtividade de grãos por área e por planta, número de síliquas por planta, número de grãos por síliqua e por planta, e massa de síliqua) e à morfologia da canola (comprimento de síliqua, número de ramos secundários, altura de inserção do ramo secundário, comprimento de ramo e número de ramos terciários). A produtividade de grãos por área e por planta apresenta maior herdabilidade no menor espaçamento entre linhas. O número de síliquas e o de grãos por planta são os componentes de produção com maior correlação direta e positiva com a produtividade de grãos.

Termos para indexação: Brassica napus, caracteres morfológicos, componentes de produção, densidade de plantio, espaçamento entre linhas.

\section{Heritability and phenotypic correlation of characters related to grain yield and morphology of canola}

\begin{abstract}
The objective of this work was to estimate the heritability and to evaluate the phenotypic correlations of canola (Brassica napus) traits related to grain yield components and plant architecture. Three experiments were carried out using $0.20,0.40$ and $0.60 \mathrm{~m}$ row spacing. During two crop years (2008 and 2009), the genotypes 'Hyola 432' and 'Hyola 61' were evaluated at plant densities of 20, 40, 60 and 80 plants per square meter in each experiment. A complete block experimental design was used in a $2 \times 2 \times 4$ factorial arrangement (years $\mathrm{x}$ genotypes $\mathrm{x}$ densities), with four replicates. Evaluations were done for components linked to production (grain yield per area and per plant, number of pods per plant, number of grains per pod and per plant, and pod mass), and to the morphology of canola (pod length, number of secondary branches, height of insertion of the secondary branch, branch length and number of tertiary branches). Grain yield per area and per plant have higher heritability in the narrower row spacing. The number of pods and of seeds per plant are the components with higher direct and positive correlation with yield.
\end{abstract}

Index terms: Brassica napus, morphological traits, yield components, planting density, row spacing.

\section{Introdução}

A produtividade da canola (Brassica napus L.) está relacionada aos componentes diretos de produção densidade de plantas, número de síliquas por planta, número de grãos por síliqua e massa de grãos (Thomas, 2003). Assim, alterações promovidas nesses componentes ou em outros, de efeito indireto sobre a produtividade, como comprimento e número de ramos, podem proporcionar modificações na arquitetura da planta, na uniformidade de maturação das síliquas e na produtividade de grãos.

Se a herdabilidade é conhecida, pode-se quantificar a intensidade com que as variações de ambiente afetam a expressão dos caracteres (Amorim et al., 2008). Segundo Carvalho et al. (2001), estimativas de herdabilidade podem ser obtidas com base nos componentes da análise da variância, em experimentos com repetições com igual número de plantas ou de parcelas. 
Em estudos que visam incrementar a produtividade de grãos, é necessário observar a expressão dos componentes de produção e a relação entre eles, bem como estimar os parâmetros genéticos responsáveis pela manifestação desses caracteres (Carvalho et al., 2001). Componentes diretos e indiretos de produção têm sido estudados em diversas culturas como canola, aveia, girassol e soja (Tourino et al., 2002; Coimbra et al., 2004; Hartwig et al., 2007; Amorin et al., 2008). Esses trabalhos visam determinar quais componentes são mais sensíveis a variações nas condições ambientais. Nesse contexto, é ainda necessário determinar os efeitos da redução do espaçamento entre linhas recomendado para canola (Thomas, 2003; Shahin \& Valiollah, 2009), sobre os componentes de produção.

Medidas de correlação entre os caracteres dos componentes de produção de grãos podem auxiliar no aumento de produtividade das culturas, pois possibilitam o conhecimento dos reflexos da alteração de um caráter sobre a expressão de outros (Benin et al., 2009). A correlação fenotípica entre os caracteres é a única possível de se medir diretamente, pode auxiliar na descoberta de componentes de produção que podem ser alterados para maior produtividade de grãos (Coimbra et al., 2004).

Como a correlação fenotípica inclui simultaneamente partes atribuídas a efeitos genéticos e de ambiente, a inclusão de fontes de variação, para ambos os efeitos, pode permitir conhecer com maior fidelidade a força das relações entre os caracteres. Assim, conhecer se a expressão das variáveis é mais fortemente influenciada por efeitos genéticos ou ambientais aumenta a consistência da estimativa da herdabilidade, pelo efeito cumulativo de fontes de variação.

O objetivo deste trabalho foi estimar a herdabilidade e avaliar a correlação fenotípica entre caracteres de canola relacionados à produtividade de grãos e à arquitetura de plantas, como forma de prever a estabilidade fenotípica a partir de efeitos que envolvam, de forma conjunta, anos, genótipos e densidades de plantio.

\section{Material e Métodos}

Os experimentos foram realizados nos anos agrícolas de 2008 e 2009, no Instituto Regional de Desenvolvimento Rural, do Departamento de Estudos
Agrários, da Universidade Regional do Noroeste do Estado do Rio Grande do Sul (Unijuí), no Município de Augusto Pestana, RS, a $28^{\circ} 26^{\prime} 30^{\prime \prime} \mathrm{S}, 54^{\circ} 00^{\prime} 58^{\prime \prime} \mathrm{W}$ e à altitude média de $298 \mathrm{~m}$. O solo da área experimental é classificado como Latossolo Vermelho distroférrico típico (Santos et al., 2006). O clima da região, segundo classificação de Köppen, é do tipo $\mathrm{Cfa}$, com verão quente sem estação seca.

O trabalho envolveu a realização de três experimentos, com três espaçamentos entre linhas: 0,20, 0,40 e 0,60 m. Em cada experimento, empregouse o delineamento de blocos ao acaso, com quatro repetições, em arranjo fatorial $2 \times 2 \times 4$. Os fatores de variação considerados foram: ano de cultivo (2008 e 2009), genótipo ('Hyola 432' e 'Hyola 61' ) e densidade de plantas (20, 40, 60 e 80 plantas por metro quadrado). A unidade experimental foi constituída por cinco linhas de cinco metros de comprimento. Portanto, a dimensão das parcelas experimentais foi alterada de acordo com o espaçamento entre linhas adotado, com parcelas de $5(0,20 \mathrm{~m}), 10(0,40 \mathrm{~m})$ e $15 \mathrm{~m}^{2}(0,60 \mathrm{~m})$.

A correção e a adubação foram feitas de acordo com a análise de solo, para uma expectativa de produtividade de grãos de aproximadamente $1.500 \mathrm{~kg} \mathrm{ha}{ }^{-1}$. A semeadura foi realizada de forma manual, na terceira semana de maio, com quantidade de sementes superior à mínima necessária para cada densidade avaliada. No estádio de duas a três folhas, as plantas foram desbastadas de forma a se obter em as densidades de plantas desejadas.

A produtividade de grãos ( $\mathrm{PG}$ ) foi determinada pela colheita manual total da parcela, com posterior conversão para quilogramas por hectare. Para as avaliações das plantas, individualmente, foram colhidas aleatoriamente cinco plantas, a fim de se compor a média dos seguintes caracteres: produtividade de grãos por planta (PGP, em gramas por planta); número de síliquas por planta (NSP); número de grãos por síliquas (NGS), obtido pela média da contagem dos grãos de 20 síliquas por planta escolhida ao acaso; número de grãos por planta (NGP), obtido pelo produto entre o NSP e o NGS; massa de síliqua (MS, g), obtida pela média da pesagem das 20 síliquas com grãos coletadas ao acaso; comprimento de síliqua $(\mathrm{CS}, \mathrm{cm})$, obtido a partir de medição com régua do comprimento médio das 20 síliquas amostradas para a determinação do NGS; número de ramos secundários (NRS), obtido pela contagem de todos os ramos inseridos no caule 
principal da planta; altura de inserção do primeiro ramo secundário (AIRS, $\mathrm{cm}$ ), obtido pela medição com régua entre o ponto de corte, na superfície do solo, até a inserção da primeira ramificação; comprimento de ramo secundário $(\mathrm{CR}, \mathrm{cm})$, obtido pela medição com régua da inserção do primeiro ramo no caule principal até sua extremidade; número de ramos terciários (NRT), pela contagem dos ramos provenientes dos ramos secundários; e estatura da planta (EST, $\mathrm{cm})$, medida com régua do ponto de corte da planta, na superfície do solo, até o ápice da planta.

Os dados foram submetidos ao modelo de correlação de Pearson para obtenção da magnitude e sentido de associações entre as variáveis estudadas, conforme Falconer \& Mackay (1996). A significância das correlações foi avaliada a 5\% de probabilidade, tendose adotado o teste t, descrito por Steel \& Torrie (1980), com $\mathrm{n}$ - 2 graus de liberdade, de acordo com o modelo $\mathrm{t}=\mathrm{r} /\left[\left(1-\mathrm{r}^{2}\right) /(\mathrm{n}-2)\right]^{0,5}$, em que $\mathrm{r}$ é o coeficiente de correlação entre os caracteres $\mathrm{X}$ e $\mathrm{Y}$, e $\mathrm{n}$ o número de graus de liberdade nos níveis de tratamentos considerados, no total de $n=64$ unidades de observação: dois anos, dois genótipos e quatro densidades de plantio, com quatro repetições. A partir daí, foi realizada a análise de variância dos tratamentos, que englobaram o efeito cumulativo de ano, genótipo e densidade de plantas, para obtenção dos valores de quadrado médio necessários à determinação dos parâmetros genéticos, como forma de se conhecer a estabilidade dos caracteres agronômicos mensurados, segundo Carvalho et al. (2001). Para estas determinações, foi empregado o programa Genes (Cruz, 2001).

\section{Resultados e Discussão}

As estimativas de herdabilidade $\left(\mathrm{h}^{2}\right)$ para PGP e PG foram mais elevadas no espaçamento entre linhas de $0,20 \mathrm{~m}$, em comparação aos demais espaçamentos (Tabela 1). Os componentes diretos de produtividade de grãos, NSP e NGP, também apresentaram maiores $\mathrm{h}^{2}$ nesse espaçamento $(0,87$ e 0,80 , respectivamente). Em estudos com feijão e girassol, a herdabilidade de caracteres diretamente ligados à produção de grãos foi baixa (Londero et al., 2006; Amorin et al., 2008). Os autores ressaltaram que esses caracteres são de herança quantitativa e, portanto, são governados por grande número de genes de pequeno efeito cumulativo para a expressão do caráter e fortemente responsivos a mudanças no ambiente. Portanto, as elevadas magnitudes de $h^{2}$ para esses caracteres mostram que a redução do espaçamento entre linhas promoveu maior uniformidade de plantas, já que, caso contrário, a desuniformidade no ponto de colheita, em razão do crescimento indeterminado da espécie, teria causado grande perda de grãos pela abertura natural da síliquas (Silva et al., 2011), o que tornaria difícil a obtenção dos altos valores de $\mathrm{h}^{2}$ observados para esses caracteres.

Para NGS e MS, foram observadas magnitudes intermediárias de herdabilidade com valores de 0,56 e 0,55 , respectivamente, no espaçamento de $0,20 \mathrm{~m}$ (Tabela 1). Os caracteres de arquitetura de planta, como NRS, AIRS e NRT, também mostraram valores médios de $\mathrm{h}^{2}$, ao contrário de CR e EST, que apresentaram valores reduzidos de $h^{2}$. Estas observações indicam que, sob condições de menor espaçamento entre linhas, CR e EST são as variáveis de maior tendência à alteração.

No espaçamento de $0,40 \mathrm{~m}$, foram obtidas $\mathrm{h}^{2}$ médias para PG $(0,60)$ e PGP $(0,62)$, em comparação ao espaçamento de $0,20 \mathrm{~m}$ (Tabela 1). Quanto aos demais componentes de produção, como NSP, NGS e NGP, também foram observados menores valores em comparação ao espaçamento de $0,20 \mathrm{~m}$. Portanto, no espaçamento de $0,40 \mathrm{~m}$, o ambiente teve maior participação na variação fenotípica. As variáveis $C R$ e NRT mostraram maior estabilidade fenotípica (pouco afetado pela variação ambiental), o que indica efeitos mais diretamente ligados ao genótipo, com elevados valores de $\mathrm{h}^{2}$.

Em canola, os efeitos negativos que espaçamentos menores podem exercer sobre alguns caracteres, geralmente, são compensados pela maior PG (Johnson \& Hanson, 2003). Além disso, espaçamentos maiores determinam maior competição por fotoassimilados em uma mesma planta, para produzir ramos mais finos e em maior número (Thomas, 2003), o que reduz o NSP (Shahin \& Valiollah, 2009). Como a PG está diretamente relacionada à capacidade da planta de converter energia solar em órgãos e grãos, a eficiência de uso da radiação também pode ser alterada via manipulação na arquitetura de plantas (Argenta et al., 2001).

A PG e PGP, no espaçamento entre linhas $0,60 \mathrm{~m}$, apresentaram os menores valores de herdabilidade, 0,39 e 0,50 , respectivamente (Tabela 1 ). O NSP também evidenciou maior participação do ambiente em sua expressão fenotípica $\left(h^{2}=0,48\right)$, nesse espaçamento.

Pesq. agropec. bras., Brasília, v.46, n.12, p.1625-1632, dez. 2011 
Todavia, ressalta-se a elevada $h^{2}$ encontrada para o componente de produção direto NGS $(0,75)$. O CS também mostrou elevada participação genética em sua expressão $\left(h^{2}=0,71\right)$. Herdabilidade elevada também foi observada para NRT.

Foram encontrados valores reduzidos de herdabilidade para NRS $(0,30)$, AIRS $(0,37)$ e EST $(0,30)$, o que indica que a plasticidade fenotípica da espécie atua, principalmente por meio desses caracteres, no ajuste do arranjo de plantas e no aproveitamento de área de exploração (Tabela 1). Benin et al. (2005) comentam a necessidade de se identificar, nas espécies, as modificações que maximizam o aproveitamento de estímulos do ambiente. Em canola de inverno, em

Tabela 1. Quadrados médios da análise de variância, médias, parâmetros genéticos de componentes ligados à produção e à arquitetura de plantas de canola.

\begin{tabular}{|c|c|c|c|c|c|c|c|}
\hline \multirow[t]{2}{*}{ Caráter $^{(1)}$} & \multicolumn{2}{|c|}{ Análise de variância } & \multirow[t]{2}{*}{ Média } & \multicolumn{4}{|c|}{ Parâmetro genético } \\
\hline & QME & QMT & & $\sigma_{\mathrm{a}}^{2}$ & $\sigma_{f}^{2}$ & $\sigma_{g}^{2}$ & $\mathrm{~h}^{2}$ \\
\hline & \multicolumn{7}{|c|}{ Espaçamento entre linhas de $0,20 \mathrm{~m}$} \\
\hline PG & $22.218,00$ & $478.754,00$ & $1.010,00$ & $22.218,00$ & $136.352,00$ & $114.134,00$ & 0,84 \\
\hline PGP & 5,10 & 124,01 & 9,87 & 5,11 & 34,84 & 29,73 & 0,85 \\
\hline NSP & $1.653,00$ & $45.261,00$ & 216,28 & 165,00 & $12.555,00$ & $10.902,00$ & 0,87 \\
\hline NGS & 2,30 & 13,78 & 16,16 & 2,30 & 5,17 & 2,87 & 0,56 \\
\hline NGP & $1.114 .528,00$ & 18.694.117,00 & $3.684,00$ & $1.114 .528,00$ & $5.509 .425,00$ & 4.394 .897 & 0,80 \\
\hline MS & 0,06 & 0,35 & 0,08 & 0,06 & 0,13 & 0,07 & 0,55 \\
\hline $\mathrm{CS}$ & 0,10 & 0,32 & 5,70 & 0,11 & 0,16 & 0,05 & 0,32 \\
\hline NRS & 0,20 & 0,83 & 3,92 & 0,22 & 0,37 & 0,15 & 0,41 \\
\hline AIRS & 22,55 & 143,20 & 32,01 & 22,55 & 52,71 & 30,16 & 0,57 \\
\hline CR & 46,15 & 119,18 & 72,29 & 46,15 & 64,41 & 18,26 & 0,28 \\
\hline NRT & 1,76 & 14,25 & 4,93 & 1,76 & 4,88 & 3,12 & 0,64 \\
\hline \multirow[t]{2}{*}{ EST } & 67,59 & 98,00 & 102,83 & 67,59 & 75,19 & 7,60 & 0,10 \\
\hline & \multicolumn{7}{|c|}{ Espaçamento entre linhas de $0,40 \mathrm{~m}$} \\
\hline PG & $29.442,00$ & $204.226,00$ & 941,00 & $29.442,00$ & $73.138,00$ & $43.696,00$ & 0,60 \\
\hline PGP & 12,14 & 91,39 & 11,61 & 12,14 & 31,95 & 19,81 & 0,62 \\
\hline NSP & $5.035,00$ & 22158 & 237,37 & 5035 & 9316 & 4281 & 0,46 \\
\hline NGS & 2,23 & 10,94 & 16,30 & 2,23 & 4,41 & 2,18 & 0,49 \\
\hline NGP & $1.582 .436,00$ & $7.488 .526,00$ & $4.223,00$ & $1.582 .436,00$ & $3.058 .959,00$ & $1.476 .523,00$ & 0,48 \\
\hline MS & 0,28 & 0,76 & 0,09 & 0,28 & 0,40 & 0,12 & 0,30 \\
\hline $\mathrm{CS}$ & 0,17 & 0,72 & 5,75 & 0,17 & 0,31 & 0,14 & 0,45 \\
\hline NRS & 0,18 & 0,91 & 3,99 & 0,18 & 0,36 & 0,18 & 0,50 \\
\hline AIRS & 33,12 & 132,81 & 34,03 & 33,12 & 58,04 & 24,92 & 0,43 \\
\hline CR & 37,8 & 394,58 & 73,72 & 37,80 & 127,00 & 89,20 & 0,70 \\
\hline NRT & 1,21 & 23,95 & 5,28 & 1,21 & 6,90 & 5,69 & 0,82 \\
\hline \multirow[t]{2}{*}{ EST } & 75,63 & 214,67 & 75,63 & 75,63 & 110,39 & 34,76 & 0,31 \\
\hline & \multicolumn{7}{|c|}{ Espaçamento entre linhas de $0,60 \mathrm{~m}$} \\
\hline PG & $17.305,00$ & $61.443,00$ & 848,00 & $17.305,00$ & $28.340,00$ & $11.035,00$ & 0,39 \\
\hline PGP & 20,22 & 115,53 & 17,60 & 20,22 & 44,05 & 23,83 & 0,54 \\
\hline NSP & $7.475,00$ & $35.615,00$ & 331,00 & $7.475,00$ & $14.510,00$ & $7.035,00$ & 0,48 \\
\hline NGS & 2,11 & 27,90 & 16,52 & 2,11 & 8,56 & 6,45 & 0,75 \\
\hline NGP & $2.400 .429,00$ & 10511770,00 & $6.273,00$ & $2.400 .429,00$ & $4.428 .264,00$ & $2.027 .835,00$ & 0,46 \\
\hline MS & 0,05 & 0,33 & 0,09 & 0,05 & 0,12 & 0,07 & 0,58 \\
\hline $\mathrm{CS}$ & 0,06 & 0,64 & 5,78 & 0,06 & 0,21 & 0,15 & 0,71 \\
\hline NRS & 0,36 & 0,97 & 4,28 & 0,36 & 0,51 & 0,15 & 0,30 \\
\hline AIRS & 29,85 & 99,83 & 31,49 & 29,85 & 47,35 & 17,50 & 0,37 \\
\hline CR & 57,62 & 405,96 & 78,64 & 57,62 & 144,71 & 87,09 & 0,60 \\
\hline NRT & 2,01 & 56,44 & 7,05 & 2,01 & 15,62 & 13,61 & 0,87 \\
\hline EST & 74,14 & 198,52 & 109,06 & 74,14 & 105,24 & 31,10 & 0,30 \\
\hline
\end{tabular}

(1)PG, produtividade de grãos (kg ha $\left.{ }^{-1}\right)$; PGP, produtividade de grãos por planta (gramas por planta); NSP, número de síliquas por planta; NGS, número de grãos por síliqua; NGP, número de grãos por planta; MS, massa de síliqua (g); CS, comprimento de síliqua (cm); NR, número de ramos secundários; AIRS, altura de inserção do ramo secundário $(\mathrm{cm})$; CR, comprimento de ramo $(\mathrm{cm})$; NRT, número de ramos terciários; EST, estatura de planta (cm). QME, quadrado médio do erro; QMT, quadrado médio de tratamento; $\sigma_{\mathrm{a}}^{2}$, variância de ambiente; $\sigma_{\mathrm{f}}^{2}$, variância fenotípica; $\sigma_{\mathrm{g}}^{2}$, variância genética; $h^{2}$, herdabilidade. 
condições de alta densidade de plantas, Leach et al. (1999) não constataram alterações significativas em PG e nos componentes diretos de produção, em razão de diferentes densidades populacionais.

$\mathrm{Na}$ análise de correlação entre caracteres, no espaçamento de $0,20 \mathrm{~m}$, a PGP apresentou baixa correlação com a PG (Tabela 2). No entanto, a significância da correlação suporta a possibilidade de utilização de PGP como subsídio para a estimativa de PG. Os caracteres NSP e NGP também apresentaram correlação significativa e positiva com PG, indício de que o favorecimento na expressão desses caracteres pode aumentar a produtividade de grãos. Observouse correlação negativa entre NGS e PG. De acordo com Thomas (2003), a maior demanda de energia pela planta, para a manutenção do óvulo fertilizado, tem efeitonegativo sobrePG.Assim, em razão da competição por fotoassimilados, a planta diminui NSP para garantir que as síliquas formadas suportem o enchimento de vários grãos, já que, segundo Silva et al. (2011),

Tabela 2. Coeficientes de correlação fenotípica de componentes ligados à produção e à arquitetura em canola.

\begin{tabular}{|c|c|c|c|c|c|c|c|c|c|c|c|}
\hline Caráter $^{(1)}$ & PGP & NSP & NGS & NGP & MS & $\mathrm{CS}$ & NRS & AIRS & $\mathrm{CR}$ & NRT & EST \\
\hline & \multicolumn{11}{|c|}{ Espaçamento entre linhas de $0,20 \mathrm{~m}$} \\
\hline PG & $0,36^{*}$ & $0,31 *$ & $-0,44^{*}$ & $0,26^{*}$ & $-0,28 *$ & $-0,19$ & $0,23 *$ & 0,07 & $-0,15$ & $-0,27^{*}$ & 0,01 \\
\hline PGP & & $0,96 *$ & 0,18 & $0,95^{*}$ & 0,06 & $-0,04$ & 0,18 & $-0,33 *$ & 0,18 & 0,08 & $-0,02$ \\
\hline NSP & & & 0,17 & $0,97 *$ & 0,01 & $-0,06$ & 0,14 & $-0,29 *$ & 0,15 & 0,02 & $-0,01$ \\
\hline NGS & & & & 0,21 & $0,47^{*}$ & $0,52 *$ & $-0,18$ & 0,15 & 0,22 & $0,24^{*}$ & $0,24^{*}$ \\
\hline NGP & & & & & 0,01 & $-0,07$ & 0,10 & $-0,29 *$ & 0,18 & 0,02 & 0,07 \\
\hline MS & & & & & & $0,59 *$ & 0,11 & $-0,31 *$ & $0,48 *$ & $0,42 *$ & $0,30 *$ \\
\hline $\mathrm{CS}$ & & & & & & & 0,12 & $-0,30 *$ & $0,38^{*}$ & $0,31^{*}$ & 0,18 \\
\hline NRS & & & & & & & & $-0,47^{*}$ & $0,49 *$ & $0,37^{*}$ & 0,08 \\
\hline AIRS & & & & & & & & & $-0,66^{*}$ & $0,48 *$ & $0,25^{*}$ \\
\hline CR & & & & & & & & & & $0,51^{*}$ & $0,34 *$ \\
\hline \multirow[t]{2}{*}{ NRT } & & & & & & & & & & & 0,09 \\
\hline & \multicolumn{11}{|c|}{ Espaçamento entre linhas de $0,40 \mathrm{~m}$} \\
\hline PG & $0,61 *$ & $0,57 *$ & $-0,36^{*}$ & $0,51 *$ & $-0,15$ & $-0,01$ & 0,22 & 0,21 & $-0,29 *$ & $-0,31^{*}$ & $-0,07$ \\
\hline PGP & & $0,93 *$ & $-0,18$ & $0,92 *$ & 0,17 & 0,17 & $-0,63 *$ & $-0,24^{*}$ & 0,18 & 0,08 & 0,11 \\
\hline NSP & & & $-0,27^{*}$ & $0,98 *$ & 0,11 & $-0,04$ & $0,52 *$ & $-0,22$ & 0,17 & $-0,01$ & 0,04 \\
\hline NGS & & & & $-0,20$ & $0,40 *$ & $0,59 *$ & $-0,13$ & $-0,09$ & $0,35 *$ & $0,52 *$ & $0,39 *$ \\
\hline NGP & & & & & 0,12 & $-0,03$ & $0,54 *$ & $-0,25^{*}$ & 0,20 & 0,01 & 0,05 \\
\hline MS & & & & & & $0,44 *$ & $0,24 *$ & $-0,35^{*}$ & $0,55^{*}$ & $0,62 *$ & $0,36^{*}$ \\
\hline $\mathrm{CS}$ & & & & & & & $0,23 *$ & $-0,14$ & $0,29 *$ & $0,43^{*}$ & $0,38 *$ \\
\hline NRS & & & & & & & & $-0,37 *$ & $0,35 *$ & 0,18 & 0,15 \\
\hline AIRS & & & & & & & & & $-0,64 *$ & $-0,49 *$ & $-0,01$ \\
\hline $\mathrm{CR}$ & & & & & & & & & & $0,74 *$ & $0,63 *$ \\
\hline \multirow[t]{2}{*}{ NRT } & & & & & & & & & & & $0,46^{*}$ \\
\hline & \multicolumn{11}{|c|}{ Espaçamento entre linhas de $0,60 \mathrm{~m}$} \\
\hline PG & $0,45^{*}$ & $0,40 *$ & $-0,21$ & $0,43 *$ & 0,08 & 0,15 & 0,13 & 0,24 & $-0,14$ & $-0,21$ & $-0,02$ \\
\hline PGP & & $0,81 *$ & $-0,02$ & $0,84^{*}$ & $0,23^{*}$ & $0,44^{*}$ & $0,39 *$ & $-0,10$ & 0,21 & 0,18 & 0,19 \\
\hline NSP & & & $-0,17$ & $0,97^{*}$ & 0,07 & 0,20 & $0,47 *$ & $-0,05$ & 0,16 & 0,14 & 0,13 \\
\hline NGS & & & & $-0,13$ & $0,67^{*}$ & $0,70^{*}$ & 0,22 & $-0,50 *$ & $0,60 *$ & $0,62 *$ & $0,46^{*}$ \\
\hline NGP & & & & & 0,08 & 0,22 & $0,45^{*}$ & $-0,05$ & 0,17 & 0,12 & 0,15 \\
\hline MS & & & & & & $0,80 *$ & $0,39 *$ & $-0,39 *$ & $0,53 *$ & $0,59^{*}$ & $0,43^{*}$ \\
\hline $\mathrm{CS}$ & & & & & & & $0,37 *$ & $-0,37^{*}$ & $0,63 *$ & $0,60 *$ & $0,53 *$ \\
\hline NRS & & & & & & & & $-0,56^{*}$ & $0,56^{*}$ & $0,59^{*}$ & $0,25^{*}$ \\
\hline AIRS & & & & & & & & & $-0,67^{*}$ & $-0,68 *$ & $-0,12$ \\
\hline $\mathrm{CR}$ & & & & & & & & & & $0,81 *$ & $0,72 *$ \\
\hline NRT & & & & & & & & & & & $0,46^{*}$ \\
\hline
\end{tabular}

(1)PG, produtividade de grãos ( $\mathrm{kg} \mathrm{ha}^{-1}$ ); PGP, produtividade de grãos por planta(gramas por planta); NSP, número de síliquas por planta; NGS, número de grãos por síliqua; NGP, número de grãos por planta; MS, massa de síliqua (g); CS, comprimento de síliqua (cm); NR, número de ramos secundários; AIRS, altura de inserção do ramo secundário $(\mathrm{cm})$; CR, comprimento de ramo $(\mathrm{cm})$; NRT, número de ramos terciários; EST, estatura de planta $(\mathrm{cm})$. *Significativo pelo teste $\mathrm{t}$, a $5 \%$ de probabilidade. 
a massa de grãos é o caráter com maior estabilidade de expressão. Quanto aos caracteres morfológicos, NRS apresentou correlação positiva com PG, e NRT negativa.

A PGP apresentou, como era de se esperar, elevadas correlações com NSP e NGP (Tabela 2). De acordo com Diepenbrok (2000), cada síliqua formada produz, no mínimo, 15 grãos. No entanto, observou-se correlação negativa entre esse caráter e AIRS.

Foram observadas correlações positivas de NGS com MS, CS, NRT e EST. É interessante observar que caracteres que conferem efeito compensatório por área, como a EST e NRT, contribuem também para a expressão de NGS. A variável MS foi positivamente influenciada pelos componentes morfológicos CS, CR, NRT e EST e negativamente por AIRS. Portanto, NRT e EST mostraram efeito direto e positivo sobre os componentes diretos NGS e MS. Contudo, o NRT foi mais efetivo em promover alterações positivas nesses caracteres do que a EST.

No espaçamento de $0,40 \mathrm{~m}$, observou-se incremento da correlação de PG com PGP, NSP e NGP (Tabela 2). Nesse espaçamento, no entanto, MS e NRS deixaram de ter efeito significativo sobre PG. A correlação negativa de PG com NGS diminuiu, e a com NRT aumentou. Além disso, o CR também passou a ter efeito negativo sobre PG. A PGP voltou a mostrar elevadas correlações com o NSP e NGP e correlação negativa com AIRS. No espaçamento de $0,40 \mathrm{~m}$ foi observada correlação negativa de alta magnitude entre PGP e NRS.

No espaçamento de $0,40 \mathrm{~m}$, observou-se relação positiva entre NGP e NRS (Tabela 2). Esse resultado indica que a tendência de incremento em NRS, em resposta ao aumento no espaçamento, aumentou NSP e, por consequência, também o NGP. Além disto, a EST mostrou efeitos positivos e significativos em NGS, MS, CS, CR e NRT, nesse espaçamento.

No espaçamento entre linhas de $0,60 \mathrm{~m}$, observaramse correlações intermediárias de PG com PGP, NSP e NGP, em comparação aos espaçamentos anteriores (Tabela 2). Além disso, observaram-se menores valores de correlação de PGP com NSP e NGP. O NRS foi o único caráter ligado à arquitetura da planta correlacionado a NSP e NGP, nesse espaçamento. Para PGP, o CS também apresentou correlação significativa e positiva. O NGS apresentou os maiores valores de correlação direta com MS e CS, em comparação aos valores observados nos demais espaçamentos.
A ausência de associação entre NGS e PG, no espaçamento de $0,60 \mathrm{~m}$, pode estar relacionada à deiscência da síliqua no momento da colheita, em razão da desuniformidade de maturação proporcionada pelo incremento do comprimento de ramos; Coimbra et al. (2004) relatam que esse componente é estreitamente relacionado a $\mathrm{PG}$.

O CR apresentou elevada correlação positiva com NRT e EST. A EST correlacionou-se, sempre positivamente, com um maior número de componentes de produção, no espaçamento de $0,60 \mathrm{~m}$. Silva et al. (2011)comentam que espaçamentos maiores em canola podem promover a maior expressão de componentes ligados à arquitetura da planta, como forma de ajuste no dossel, tendendo, porém, a alterações negativas nos componentes diretos ligados à produtividade de grãos.

Em feijão-caupi sob diferentes espaçamentos entre linhas e densidades na linha, não foram observadas modificações nos caracteres número de nós no ramo principal, número de grãos por vagem e peso de 100 grãos; porém, densidades maiores promoveram reduções no número de ramos laterais e número de vagens e de grãos por planta (Bezerra et al., 2009). Em soja, Tourino et al. (2002) observaram modificações na arquitetura de plantas e na PG, quando foi alterado o arranjo de plantas, com forte ligação do genótipo na modificação da arquitetura de planta. Em milho, aumentos na produtividade de grãos foram constatados com a redução do dossel, e o número de grãos por área foi o componente de produção maximizado com a diminuição do espaçamento entre linhas (Strieder et al., 2008). Em trigo, o uso de diferentes densidades de cultivo pôde determinar incrementos na produtividade de grãos, e a distribuição equidistante de sementes por área foi a variável que contribuiu para a maior produtividade (Silveira et al., 2010). Em canola, Coimbra et al. (2004) observaram que, com elevada densidade de plantas, os componentes número de plantas por unidade de área e de grãos por planta apresentam maior relação com a produtividade de grãos.

$\mathrm{Na}$ análise conjunta dos três espaçamentos entre linhas, a partir das médias gerais de densidades de planta e anos de cultivo, observou-se diminuição de PG com o aumento do espaçamento entre linhas (Tabelas 1 e 2). Para a PGP, no entanto, observou-se o contrário, o que também ocorreu com os demais 
caracteres diretos de produção, com exceção de NGS, que apresentou comportamento estável.

As variáveis ligadas à arquitetura MS, AIRS, CR e NRT mostraram tendência de aumento com o acréscimo no espaçamento entre linhas. Ressalta-se que, com o maior espaçamento, PG e PGP também mostraram redução nos valores de herdabilidade, indício de que são mais estáveis nos menores espaçamentos, ao contrário de CS e NRT.

As correlações positivas entre PG e os componentes NSP e NGP foram observadas nos três espaçamentos estudados. A PGP e os caracteres NSP e NGP também apresentaram correlações positivas e de elevada magnitude. A relação de NSP com PG mostrou magnitude média nos espaçamentos de 0,20 e $0,40 \mathrm{~m}$ e ausência de correlação com PGP.

\section{Conclusões}

1. A produtividade de grãos por área e por planta apresenta maior herdabilidade no menor espaçamento entre linhas.

2. Os caracteres número de síliquas e número de grãos por planta apresentam maior correlação direta e positiva com a produtividade de grãos.

\section{Referências}

AMORIM, E.P.; RAMOS, N.P.; UNGARO, M.R.G.; KIIHL, T.A.M. Correlações e análise de trilha em girassol. Bragantia, v.67, p.307-316, 2008.

ARGENTA, G.; SILVA, P.R.F. da; SANGOI, L. Arranjo de plantas em milho: análise do estado-da-arte. Ciência Rural, v.31, p.1075-1084, 2001.

BENIN, G.; CARVALHO, F.I.F. de; OLIVEIRA, A.C.; LORENCETTI, C.; VIEIRA, E.A.; COIMBRA, J.L.M.; VALÉRIO, I.P.; FLOSS, E.L.; BERTAN, I.; SILVA, G.O. da. Adaptabilidade e estabilidade em aveia em ambientes estratificados. Ciência Rural, v.35, p.295-302, 2005.

BENIN, G.; SILVA, G.O. da; PAGLIOSA, E.S.; LEMES, C.; SIGNORINI, A.; BECHE, E.; CAPELIN, M.A. Capacidade de combinação em genótipos de trigo estimada por meio de análise multivariada. Pesquisa Agropecuária Brasileira, v.44, p.1145-1151, 2009.

BEZERRA, A.A. de C.; TÁVORA, F.J.A.; FREIRE FILHO, F.R.; RIBEIRO, V.Q. Características de dossel e de rendimento em feijão-caupi ereto em diferentes densidades populacionais. Pesquisa Agropecuária Brasileira, v.44, p.1239-1245, 2009.

CARVALHO, F.I.F. de; SILVA, S.A.; KUREK, A.J.; MARCHIORO, V.S. Estimativas e implicações da herdabilidade como estratégia de seleção. Pelotas: UFPel, 2001. 99p.
COIMBRA, J.L.M.; GUIDOLIN, A.F.; ALMEIDA, M.L. de; SANGOI, L.; ENDER, M.; MEROTTO JÚNIOR, A. Análise de trilha dos componentes do rendimento de grãos em genótipos de canola. Ciência Rural, v.34, p.1421-1428, 2004.

CRUZ, C.D. Programa Genes: versão Windows: aplicativo computacional em genética e estatística. Viçosa: UFV, 2001. 648 p.

DIEPENBROK, W. Yield analysis of winter oilseed rape (Brassica napus L.): a review. Field Crops Research, v.67, p.35-49, 2000.

FALCONER, D.S.; MACKAY, T.F.C. Introduction to quantitative genetics. Harlow: Longman, 1996. 464p.

HARTWIG, I.; CARVALHO, F.I.F. de; OLIVEIRA, A.C. de; VIEIRA, E.A.; SILVA, J.A.G. da; BERTAN, I.; RIBEIRO, G.; FINATTO, T.; REIS, C.E.S. dos; BUSATO, C.C. Estimativa de coeficientes de correlação e trilha em gerações segregantes de trigo hexaplóide. Bragantia, v.66, p.203-218, 2007.

JOHNSON, B.L.; HANSON, B.K. Row-spacing interactions on spring canola performance in the northern great plains. Agronomy Journal, v.95, p.703-708, 2003.

LEACH, J.E.; STEVENSON, H.J.; RAINBOW, A.J.; MULLEN, L.A. Effects of high plant populations on the growth and yield of winter oilseed rape (Brassica napus). Journal of Agricultural Science, v.132, p.173-180, 1999.

LONDERO, P.M.G.; RIBEIRO, N.D.; CARGNELUTTI FILHO, A.; RODRIGUES, J. de A.; ANTUNES, I.F. Herdabilidade dos teores de fibra alimentar e rendimento de grãos em populações de feijoeiro. Pesquisa Agropecuária Brasileira, v.41, p.51-58, 2006.

SANTOS, H.G. dos; JACOMINE, P.K.T.; ANJOS, L.H.C. dos; OLIVEIRA, V.A. de; OLIVEIRA, J.B. de; COELHO, M.R.; LUMBRERAS, J.F.; CUNHA, T.J.F. (Ed.). Sistema brasileiro de classificação de solos. 2.ed. Rio de Janeiro: Embrapa Solos, 2006. $306 \mathrm{p}$.

SHAHIN, Y.; VALIOLLAH, R. Effects of row spacing and seeding rates on some agronomical traits of spring canola (Brassica napus L.) cultivars. Journal of Central European Agriculture, v.10, p.115-122, 2009.

SILVA, J.A.G. da; MOTTA, M.B. da; WUNSCH, J.A.; CRESTANI, M.; FERNANDES, S.B.V.; BERTO, J.L.; GAVIRAGHI, F.; MARTINS, J.A.K.; WAGNER, J.F.;VALENTINI, A.P.F.; ZAMBONATO, F. Dessecação em pré-colheita como estratégia de manejo na redução de perdas por fatores de ambiente em canola. Revista Brasileira de Agrociência, v.16, p.151-158, 2011.

SILVEIRA, G. da; CARVALHO, F.I.F. de; OLIVEIRA, A.C. de; VALÉRIO, I.P.; BENIN, G.; RIBEIRO, G.; CRESTANI, M.; LUCHE, H. de S.; SILVA, J.A.G. da. Efeito da densidade de semeadura e potencial de afilhamento sobre a adaptabilidade e estabilidade em trigo. Bragantia, v.69, p.63-70, 2010.

STEEL, R.G.D.; TORRIE, J.H. Principles and procedures of statistics: a biometrical approach. $2^{\text {nd }}$ ed. New York: McGraw-Hill, 1980. 631p.

STRIEDER, M.L.; SILVA, P.R.F. da; RAMBO, L.; SANGOI, L.; SILVA, A.A.; ENDRIGO, P.C.; JANDREY, D.B. Crop management systems and maize grain yield under narrow row spacing. Scientia Agricola, v.65, p.346-353, 2008. 
THOMAS, P. Canola grower's manual. Winnipeg: Canola Council of Canada, 2003. Available at: <http://www. canolacouncil.org/canola growers manual.aspx $>$. Accessed on: 15 Sept. 2010.
TOURINO, M.C.C.; REZENDE, P.M. de; SALVADOR, N. Espaçamento, densidade e uniformidade de semeadura na produtividade e características agronômicas da soja. Pesquisa Agropecuária Brasileira, v.37, p.1071-1077, 2002.

Recebido em 17 de junho de 2011 e aprovado em 21 de outubro de 2011 